\title{
Effect of adherence to self-monitoring of diet and physical activity on weight loss in a technology-supported behavioral intervention
}

This article was published in the following Dove Press journal:

Patient Preference and Adherence

2I March 2012

Number of times this article has been viewed

Jing Wang'

Susan M Sereika ${ }^{2,3}$

Eileen R Chasens ${ }^{2}$

Linda J Ewing ${ }^{4}$

Judith T Matthews ${ }^{2,5}$

Lora E Burke 2,3

'School of Nursing, University of Texas Health Science Center at Houston, Houston, TX, ${ }^{2}$ School of Nursing, ${ }^{3}$ Graduate School of Public Health, ${ }^{4}$ School of Medicine, ${ }^{5}$ University Center for Social and Urban Research, University of Pittsburgh, Pittsburgh, PA, USA
Correspondence: Jing Wang Department of Nursing Systems,

The University of Texas Health Science Center at Houston School of Nursing, 690I Bertner Avenue, SON Room 614, Houston, TX 77030, USA

$\mathrm{Tel}+\mathrm{I} 7135009022$

Fax + I 7135002142

Email jing.wang@uth.tmc.edu
Background: Examination of mediating behavioral factors could explain how an intervention works and thus provide guidance to optimize behavioral weight-loss programs. This study examined the mediating role of adherence to self-monitoring of diet and physical activity on weight loss in a behavioral weight-loss trial testing the use of personal digital assistants (PDA) for self-monitoring.

Methods: Mediation analysis was conducted to examine the possible mediating role of adherence to self-monitoring of diet and physical activity between treatments using varying self-monitoring methods (paper record, PDA, and PDA with daily tailored feedback messages) and weight loss.

Findings: The sample $(\mathrm{N}=210)$ was predominantly white $(78 \%)$ and female $(85 \%)$. Compared to a paper record, using a PDA for self-monitoring $\operatorname{diet}(P=0.027)$ and physical activity $(P=0.014)$ had significant direct effects on weight loss at 12 months, as well as a significant indirect effect on outcomes through improved adherence to self-monitoring $\left(P_{S}<0.001\right)$. Receiving an automated daily feedback message via PDA only had a significant indirect effect on weight through self-monitoring adherence to diet $(P=0.004)$ and physical activity $(P=0.002)$.

Conclusions: Adherence to self-monitoring of diet and physical activity is important as the underlying mechanism in this technology-supported behavioral weight-loss intervention.

Keywords: behavioral intervention, self-monitoring, mobile technology, mediation analysis, weight loss, adherence

\section{Introduction}

Although much research effort is devoted to achieving and maintaining weight loss, the prevalence rates for overweight and obesity continue to be $66 \%$ for US adults. ${ }^{1}$ Standard behavioral treatment (SBT) for obesity has been shown to be efficacious in achieving weight loss; ${ }^{2,3}$ thus, optimizing SBT might lead to improved outcomes, especially for maintenance of weight loss. Because SBT involves multiple behavioral strategies, evaluation of the effectiveness of each behavioral strategy could help with the optimization process by enhancing the essential component(s).

Self-monitoring is considered the cornerstone of behavioral treatment for weight loss. ${ }^{2}$ A large body of evidence supports the role of self-monitoring in achieving successful outcomes in behavioral weight loss programs. ${ }^{4-6}$ The majority of studies used the number of submitted paper diaries ${ }^{7}$ or Internet-based diaries, ${ }^{8-11}$ or scores on a survey measuring self-monitoring ${ }^{12,13}$ as a measure of adherence to self-monitoring, which may not accurately reflect the degree of completeness of a diary. Therefore, it is important 
to examine the role of actual adherence to self-monitoring in behavioral weight loss interventions.

Mediation analysis ${ }^{14}$ has been used by previous researchers to explore the underlying mechanism of an intervention involving multiple intervention strategies. Acharya et al ${ }^{15}$ found that adherence to self-monitoring of diet was associated with weight loss. A recent literature review ${ }^{6}$ reported that using technology to support the self-monitoring process with an available food and physical activity database showed promise in improving weight loss through better self-monitoring adherence. Physical activity, another essential component of a behavioral weight loss program, may also increase if recording the number of minutes engaged in physical activity becomes an integral part of the selfmonitoring regimen. However, no study has reported the mediating effect of adherence to self-monitoring physical activity, or how such effects are sustained for long-term weight loss. The purpose of this paper is to report on the mediation effect of adherence to self-monitoring diet and physical activity on weight loss in overweight or obese participants after 12 months in a technology-based behavioral weight-loss program.

\section{Methods}

We used baseline and 12-month data from the SMART (Self-Monitoring And Recording using Technology) Weight Loss Trial. ${ }^{16}$ The SMART study was a three-group, randomized clinical trial with a standard behavioral weight-loss intervention designed to test the efficacy of three modes of self-monitoring on weight loss: (1) paper record (PR), (2) personal digital assistants (PDA) with dietary and physical activity software, and (3) PDA with the same software plus a tailored, daily feedback message (PDA + FB). The study was approved by the University of Pittsburgh Institutional Review Board. There were 210 participants at baseline; 179 participants completed the 12-month assessment (60 in the PR group, 60 in the PDA group, and 59 in the PDA + FB group). A participant flow diagram is detailed in Figure 1. Participants were 21-59 years of age and had a body mass index (BMI) between 27 and $43 \mathrm{~kg} / \mathrm{m}^{2}$.

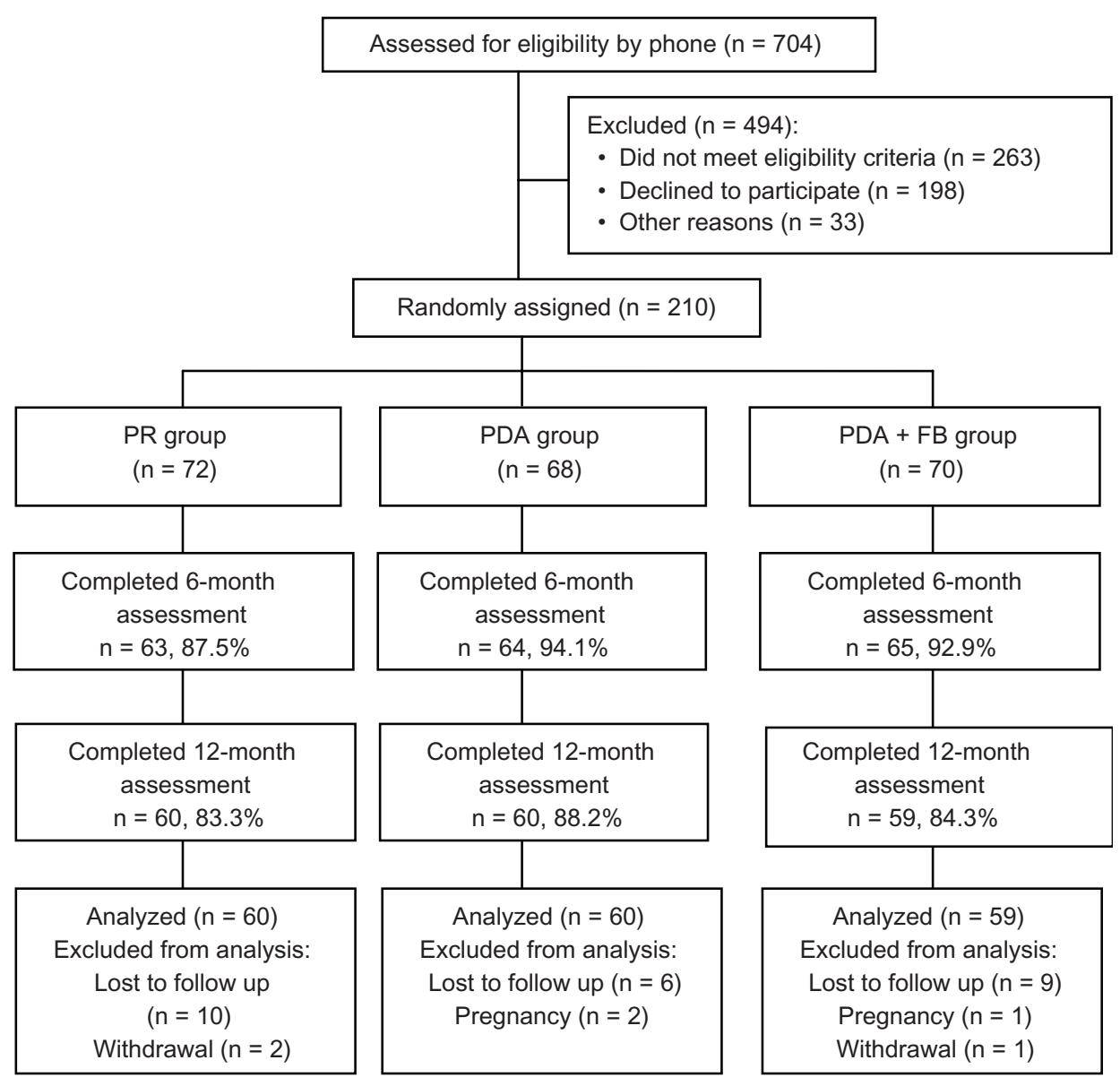

Figure I Participant flow diagram.

Abbreviations: PR, paper record; PDA, personal digital assistant; FB, feedback. 
All participants received group-based nutritional and behavioral counseling for which the detailed intervention schedule and strategies have been published elsewhere. ${ }^{17}$ Interventionists were nutritionists or exercise physiologists with training in the lifestyle behavioral intervention. There was a total of 32 group sessions during the first 12 months, each lasting approximately 45-60 minutes. The groups met weekly for the first 4 months, then bi-weekly for months 5-12. Participants in all groups received a daily calorie goal based on their baseline body weight and gender (for women, $1200 \mathrm{kcal}$ for $<200 \mathrm{lb}$ or $1500 \mathrm{kcal}$ for $\geq 200 \mathrm{lb}$; for men: $1500 \mathrm{kcal}$ for $<200 \mathrm{lb}$ or $1800 \mathrm{kcal}$ for $\geq 200 \mathrm{lb}$ ), and all participants had a daily fat gram goal of $\leq 25 \%$ of their calories. Their weekly physical activity goals were 150 minutes of moderate exercise by the 6th week of the intervention.

The treatment effect in this analysis was evaluated using two grouping variables: (1) PDAs (PDA group and PDA + FB group) versus $\mathrm{PR}$ (PR group), to evaluate the effect of using a PDA, compared to using a paper record, and (2) daily feedback [DFB] (PDA + FB group) versus no feedback (PR group and PDA group), to evaluate the effect of receiving daily tailored feedback messages versus no daily tailored feedback.

Adherence to self-monitoring of diet and physical activity was measured by the proportion of weeks when participants recorded at least $50 \%$ of the daily calorie goal or any physical activity minutes, respectively. Participants were asked to monitor their diet (food, amount, calories, and fat grams for each food entry). The PDA groups only recorded each food entry, as their calories and fat grams were calculated automatically. All participants were asked to monitor their physical activity type and minutes in either the paper diary or the electronic diary embedded in the PDA. Participants submitted diaries for a total of 32 weeks from baseline to 12 months. Each diary submitted represented a participant's diet and physical activity for the preceding week. For biweekly sessions, only the diaries from the week immediately preceding the intervention session were taken into account. This method of measuring adherence to self-monitoring of diet was used and evaluated in a previous study. ${ }^{15}$ In consultation with our interventionists and experts on adherence and self-monitoring, we decided to assume that if a participant exercised at all, he or she would be very likely to record it. Our focus was not on measuring a participant's adherence to the physical activity goal, but rather on measuring their adherence to self-monitoring of physical activity. Thus, if any minutes were recorded in a diary, we considered the participant to be adherent to self-monitoring of physical activity for that particular week. A missing diary was defined as non-adherent to self-monitoring diet or physical activity for that week.

Weight was measured by the Tanita Scale, with participants wearing light clothing but no shoes and following an overnight fast. Assessments were conducted every 6 months; we focused on the baseline and 12-month time points in this report. Participants were weighed in a private office by study personnel or their interventionist.

\section{Statistical analysis}

Mplus (v 5.21; Muthen and Muthen, Los Angeles, CA), SPSS (v 17.0; SPSS, Inc, Chicago, IL), and SAS (v 9.2; SAS Institute, Inc, Cary, NC) were used for the data analyses. Correlational and linear regression analyses were performed for each selfmonitoring adherence variable (measured by the proportion of sessions participants were adherent to self-monitoring diet/physical activity) and percent weight loss at 12 months. Covariates considered were age, gender, and ethnicity.

Baron and Kenny ${ }^{18}$ defined mediation to be the processes (mediating variables) that intervene between the stimulus (independent/proximal variable) and the response (dependent/distal variable). Observed variable path analysis was used to fit the proposed mediation models. Path coefficients with standard errors and $R^{2}$ values for the proximal (adherence to self-monitoring diet and physical activity) and distal (weight loss) endogenous variables were estimated, as depicted in Figure 2. Indirect, direct, and total effects were

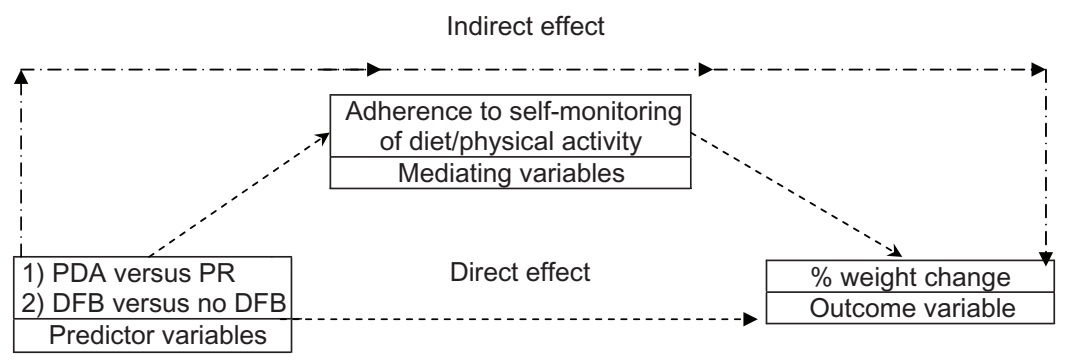

Figure 2 Mediation model.

Abbreviations: PR, paper record; PDA, personal digital assistant; DFB, daily feedback. 
also estimated. The observed variable path analysis via 5000 bootstrapping was used to test for mediation effect. Goodness-of-fit was assessed using the recommended indices including root mean square error of approximation (RMSEA) and comparative fit index (CFI). Residual analyses were performed for each path analysis model fitted to identify sources of model misspecification, outliers, and influential observations.

\section{Results}

Sociodemographic characteristics of the sample are described in Table 1. There were 179 participants who had complete data on weight at 12 months. Participants who completed the 12-month assessment were significantly older and had a lower BMI at baseline than those who did not.

Baseline and 12-month percent changes in weight, and adherence to self-monitoring diet and physical activity during the 12 months are presented in Table 2 . Regression analyses revealed that the effect of the self-monitoring approach (PR versus PDA versus PDA + FB) on adherence to selfmonitoring diet and physical activity differed significantly $\left(P_{S}<0.001\right)$, while its effect on percent change in weight was not significant $(P>0.05)$. Bivariate correlations indicated that weight changes at 12 months were associated with selfmonitoring diet $(r=-0.511, P<0.01)$ and self-monitoring physical activity $(r=-0.500, P<0.01)$. Mediation analyses revealed that, compared to using a paper record, using a PDA had a significant direct $(P=0.027)$ effect and a significant indirect effect on weight loss through improved adherence to self-monitoring diet (estimate $=2.709, P<0.001$ ). The model explained the mechanism of how adherence to selfmonitoring diet mediated the effect of using a PDA (versus paper record) on weight loss. A similar mediation effect was found for adherence to self-monitoring physical activity (direct effect: $P=0.014$; indirect effect: estimate $=2.892$, $P<0.001)$. We also found a significant indirect effect of receiving daily tailored feedback (versus no feedback) on weight loss at 12 months through improved adherence to selfmonitoring diet (estimate $=1.856, P=0.004$ ) and physical activity (estimate $=1.919, P=0.002$ ). However, no significant direct effects were detected $\left(P_{S}>0.05\right)$.

\section{Discussion}

Standard behavioral treatment involves many behavioral strategies, so it is very difficult to tease out which strategy is having an effect and contributing the most to the outcomes of interest. Our study used mediation analysis to explain the underlying mechanism of adherence to self-monitoring diet and physical activity in a standard behavioral weight-loss program using a PDA to facilitate self-monitoring. Our findings suggest that the effect of receiving a daily tailored feedback message from a PDA versus no message on long-term weight loss at 12 months was fully explained by participants' adherence to self-monitoring diet and physical activity.

Table I Baseline characteristics of the sample (completers versus non-completers)

\begin{tabular}{|c|c|c|c|c|}
\hline Characteristics & $\begin{array}{l}\text { Total sample } \\
(\mathrm{N}=210)\end{array}$ & $\begin{array}{l}\text { Completers } \\
(\mathrm{n}=179)\end{array}$ & $\begin{array}{l}\text { Non-completers } \\
(n=31)\end{array}$ & $\begin{array}{l}P \text { (completers versus } \\
\text { non-completers) }\end{array}$ \\
\hline Age (years) & $46.80 \pm 9.02$ & $47.73 \pm 8.46$ & $41.45 \pm 10.36$ & $<0.001$ \\
\hline Gender & & & & 0.695 \\
\hline Female & $84.8(178)$ & $84.3(15 \mathrm{I})$ & $87.0(27)$ & \\
\hline Male & $15.2(32)$ & I $5.7(28)$ & $13.0(4)$ & \\
\hline Ethnicity & & & & 0.400 \\
\hline White & $78.1(164)$ & $77.0(138)$ & $83.9(26)$ & \\
\hline Black & $21.9(46)$ & $23.0(4 I)$ & I6.I (5) & \\
\hline Education (years) & $15.65 \pm 3.00$ & $15.80 \pm 3.03$ & $14.77 \pm 2.68$ & 0.079 \\
\hline BMI $\left(\mathrm{kg} / \mathrm{m}^{2}\right)$ & $34.01 \pm 4.49$ & $33.69 \pm 4.42$ & $35.88 \pm 4.46$ & 0.012 \\
\hline Marital status & & & & 0.389 \\
\hline Currently married & $68.6(144)$ & $67.0(120)$ & $77.4(24)$ & \\
\hline Never married & $13.8(29)$ & $15.0(27)$ & $6.5(2)$ & \\
\hline Divorced or separated & $17.6(37)$ & $18.0(32)$ & $16.1(5)$ & \\
\hline Employment status & & & & 0.166 \\
\hline Employed full time & $82.9(174)$ & $84.3(15 I)$ & $74.2(23)$ & \\
\hline Not full time & I7.I (36) & I5.7 (28) & $25.8(8)$ & \\
\hline Gross household income & & & & 0.565 \\
\hline$>\$ 50,000$ & $60.0(123)$ & $60.9(106)$ & $54.8(17)$ & \\
\hline$\$ 30,000-\$ 50,000$ & $23.9(49)$ & $24.1(42)$ & $22.6(7)$ & \\
\hline$\$ 10,000-\$ 30,000$ & I6.I (33) & $14.9(26)$ & $22.6(7)$ & \\
\hline
\end{tabular}

Abbreviation: BMI, body mass index. 
Table 2 Percent weight loss and adherence from baseline to 12 months by treatment group

\begin{tabular}{llll}
\hline Characteristics & Paper record & PDA & PDA + FB \\
\hline Adherence to SM of diet ${ }^{\mathrm{a}}$ & $34.38(16.4 I, 75.00)^{\mathrm{b}}$ & $57.8 \mathrm{I}(34.38,87.50)$ & $71.88(36.72,88.28)$ \\
Adherence to SM of physical activity & $29.69(13.28,59.38)$ & $59.38(28.13,92.97)$ & $68.75(42.19,90.63)$ \\
Weight (Ib) & $-5.19(-9.99,-0.23)$ & $-3.92(-9.40,-1.27)$ & $-5.30(-11.75,-0.99)$ \\
\hline
\end{tabular}

Notes: a Group difference found only in adherence to self-monitoring of diet and physical activity. Adherence was measured by the proportion of weeks that they were adherent; ${ }^{b}$ median and inter-quartile range are reported, since all variables are non-normally distributed.

Abbreviations: SM, self-monitoring; PDA, Personal digital assistant group; PDA + FB, PDA with feedback group.

Studies have shown the superiority of receiving automated feedback through digital devices in lifestyle interventions. ${ }^{10,19}$ Our findings further suggest that the mechanism for achieving differences in long-term weight loss when receiving a feedback message via a PDA was due entirely to the improved self-monitoring adherence.

Our study confirmed the findings from other studies ${ }^{5,8,12,20}$ of a significant association between adherence to self-monitoring and weight loss. While others simply used the number of completed diaries to measure adherence, we used a relatively more accurate measure of adherence to self-monitoring of diet and physical activity by monitoring the diary content and using it to define adherence to self-monitoring. We also were the first to separately examine the effect of adherence to self-monitoring diet and adherence to self-monitoring physical activity. Our finding that adherence to self-monitoring of both behaviors was significantly correlated with weight loss at 12 months adds to the limited literature in the area of adherence to self-monitoring of physical activity. ${ }^{20-22}$

We also found that adherence to self-monitoring diet and physical activity mediated the effect of using a PDA (combined two PDA groups) versus a paper record for self-monitoring on weight loss. The effect of using a PDA, rather than a paper record, had a direct effect on weight loss at 12 months, as well as an indirect effect on weight loss through adherence to self-monitoring diet or physical activity. Although Yon et $\mathrm{a}^{23}$ reported that using a PDA is comparable to using a paper diary in achieving weight loss, our results suggest that using a PDA (compared to a paper record) for self-monitoring itself led to a greater weight loss, and also using a PDA to monitor diet and physical activity could achieve greater weight loss when participants selfmonitored their diet and physical activity. The difference between the study reported by Yon et al and the SMART study might be that the former used non-concurrent groups in their study whereas we used a randomized controlled trial design with concurrent groups. Other researchers have explored additional factors as possible mediators of weight loss including parents' life and family satisfaction for adolescents' weight loss and dietary practices for parents' weight loss. ${ }^{24}$ Researchers in Australia in the SHED-IT study, an Internet-based weight loss program for overweight men $(\mathrm{N}=65)$, explored the role of dietary behavior and physical activity as mediators of the intervention, but the results were not statistically significant. ${ }^{25}$

There were limitations to this study. First, our sample was comprised predominantly of well-educated, white females. Therefore, the results may not be generalizable to some ethnic minority populations, males, or less educated persons. Second, since this is a secondary analysis of existing data, the sample size was fixed. In order to achieve enough statistical power, we examined only one behavioral factor in this study, self-monitoring adherence. However, there are many other behavioral factors including self-efficacy enhancement, stimulus control, social problem solving, and goal setting that are worthy of further investigation. However, there are also strengths in our study. First, the randomized 3-group design. Second, our measurement of adherence to self-monitoring diet and physical activity was more clearly defined than what is reported by others (eg, completed diaries without a definition of what constitutes completed, or the number of diaries submitted). Finally, we had a $22 \%$ representation of blacks in our study.

In conclusion, our study findings concur with previous studies that self-monitoring is the most influential factor in achieving and maintaining weight loss. In addition, we found that use of a PDA increases self-monitoring and that the addition of personalized messages on a PDA has an additive effect on increasing adherence to self-monitoring. Using a PDA for self-monitoring diet and physical activity had a direct effect on weight loss and an indirect effect on weightloss maintenance at 12 months through self-monitoring adherence, whereas receiving daily tailored feedback messages via a PDA had only an indirect effect on weight-loss maintenance through self-monitoring adherence. Further investigation of self-monitoring adherence in a larger sample with a longer follow-up is a reasonable endeavor to provide stronger evidence for the optimization of the SBT through improved self-monitoring. Also, considering that the PDA as a standalone device has become obsolete, future studies need 
to examine the use of current technology such as smartphones with self-monitoring apps for diet and physical activity. Self-monitoring adherence may be facilitated by the convenience of carrying only one device.

\section{Acknowledgments}

The parent study was supported by NIH/NIDDK \# R01 DK071817. The conduct of the parent study was also supported by the Data Management Core of the Center for Research in Chronic Disorders NIH-NINR \#P30-NR03924, the General Clinical Research Center, NIH-NCRR-GCRC \#5M01-RR000056 and the Clinical Translational Research Center, NIH/NCRR/CTSA Grant UL1 RR024153 at the University of Pittsburgh. Dr Burke was partially supported by NIH/NINR K24 NR010742.

\section{Disclosure}

The authors report no conflicts of interest in this work.

\section{References}

1. Flegal KM, Carroll MD, Ogden CL, Curtin LR. Prevalence and trends in obesity among US adults, 1999-2008. JAMA. 2010;303(3):235-241.

2. Wing RR. Behavioral approaches to the treatment of obesity. In: Bray GA, Bourchard C, James WPT, editors. Handbook of Obesity: Clinical Applications. 2nd ed. New York: Marcel Dekker; 2004: 147-167.

3. Wadden TA, Crerand CE, Brock J. Behavioral treatment of obesity. Psychiatr Clin North Am. 2005;28(1):151-170.

4. Baker RC, Kirschenbaum DS. Self-monitoring may be necessary for successful weight control. Behav Ther. 1993;24:377-394.

5. Boutelle KN, Kirschenbaum DS. Further support for consistent selfmonitoring as a vital component of successful weight control. Obes Res. 1998;6(3):219-224.

6. Burke LE, Wang J, Sevick MA. Self-monitoring in weight loss: a systematic review of the literature. J Am Diet Assoc. 2011;111(19):92-102.

7. Helsel DL, Jakicic JM, Otto AD. Comparison of techniques for selfmonitoring eating and exercise behaviors on weight loss in a correspondence-based intervention. Am Diet Assoc. 2007;107(10):1807-1810.

8. Tate DF, Wing RR, Winett RA. Using Internet technology to deliver a behavioral weight loss program. JAMA. 2001;285(9):1172-1177.

9. Webber KH, Tate DF, Ward DS, Bowling JM. Motivation and its relationship to adherence to self-monitoring and weight loss in a 16-week Internet behavioral weight loss intervention. J Nutr Educ Behav. 2010;42(3):161-167.

10. Tate DF, Jackvony EH, Wing RR. A randomized trial comparing human e-mail counseling, computer-automated tailored counseling, and no counseling in an Internet weight loss program. Arch Intern Med. 2006;166(15):1620-1625.
11. Tate DF, Jackvony EH, Wing RR. Effects of Internet behavioral counseling on weight loss in adults at risk for type 2 diabetes: A randomized trial. JAMA. 2003;289(14):1833-1836.

12. Butryn ML, Phelan S, Hill JO, Wing RR. Consistent self-monitoring of weight: a key component of successful weight loss maintenance. Obesity (Silver Spring). 2007;15(12):3091-3096.

13. Nothwehr F, Peterson NA. Healthy eating and exercise: strategies for weight management in the rural midwest. Health Educ Behav. 2005;32(2):253-263.

14. Baron RM, Kenny DA. The moderator-mediator variable distinction in social psychological research: conceptual, strategic, and statistical considerations. J Pers Soc Psychol. 1986;51(6):1173-1182.

15. Acharya SD, Elci OU, Sereika SM, et al. Adherence to a behavioral weight loss treatment program enhances weight loss and improvements in biomarkers. Patient Prefer Adherence. 2009;3:151-160.

16. Burke LE, Conroy MB, Sereika SM, et al. The effect of electronic selfmonitoring on weight loss and dietary intake: a randomized behavioral weight loss trial. Obesity (Silver Spring). 2011;19(2):338-344.

17. Burke LE, Choo J, Music E, et al. PREFER study: a randomized clinical trial testing treatment preference and two dietary options in behavioral weight management - rationale, design and baseline characteristics. Contemp Clin Trials. 2006;27(1):34-48.

18. Baron RM, Kenny DA. The moderator-mediator variable distinction in social psychological research: conceptual, strategic, and statistical considerations. J Pers Soc Psychol. 1986;51(6):1173-1182.

19. Blanson Henkemans OA, van der Boog PJ, Lindenberg J, et al. An online lifestyle diary with a persuasive computer assistant providing feedback on self-management. Technol Health Care. 2009;17(3):253-267.

20. Burke LE, Wang J, Sevick MA. Self-monitoring in weight loss: a systematic review of the literature. J Am Diet Assoc. 2011;111(1): 92-102.

21. Carels RA, Darby LA, Rydin S, Douglass OM, Cacciapaglia HM, O'Brien WH. The relationship between self-monitoring, outcome expectancies, difficulties with eating and exercise, and physical activity and weight loss treatment outcomes. Ann Behav Med. 2005;30(3):182-190.

22. Conroy MB, Yang K, Elci EU, et al. Physical activity self-monitoring and weight loss: 6-month results of the SMART trial. Med Sci Sports Exerc. 2011;43(8):1568-1574.

23. Yon BA, Johnson RK, Harvey-Berino J, Gold BC, Howard AB. Personal digital assistants are comparable to traditional diaries for dietary self-monitoring during a weight loss program. J Behav Med. 2007;30(2):165-175.

24. White MA, Martin PD, Newton RL, et al. Mediators of weight loss in a family-based intervention presented over the internet. Obes Res. 2004;12(7):1050-1059.

25. Lubans DR, Morgan PJ, Collins CE, Warren JM, Callister R. Exploring the mechanisms of weight loss in the SHED-IT intervention for overweight men: a mediation analysis. Int $J$ Behav Nutr Phys Act. 2009;6:76.
Patient Preference and Adherence

\section{Publish your work in this journal}

Patient Preference and Adherence is an international, peer-reviewed, open access journal focusing on the growing importance of patient preference and adherence throughout the therapeutic continuum. Patient satisfaction, acceptability, quality of life, compliance, persistence and their role in developing new therapeutic modalities and compounds to

\section{Dovepress}

optimize clinical outcomes for existing disease states are major areas of interest. This journal has been accepted for indexing on PubMed Central. The manuscript management system is completely online and includes a very quick and fair peer-review system. Visit http://www.dovepress.com/ testimonials.php to read real quotes from published authors. 